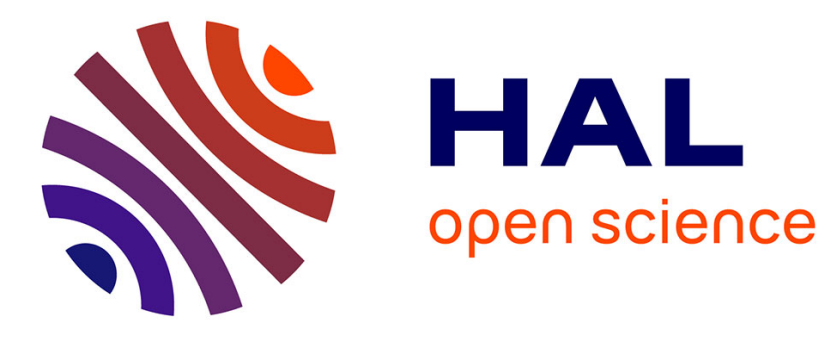

\title{
Controlled Release Carriers of Growth Factors FGF-2 and TGF 1: Synthesis, Characterization and Kinetic Modelling
}

Nader Kalaji, Alexander Deloge, Nida Sheibat-Othman, Olivier Boyron, Imad About, Hatem Fessi

\section{To cite this version:}

Nader Kalaji, Alexander Deloge, Nida Sheibat-Othman, Olivier Boyron, Imad About, et al.. Controlled Release Carriers of Growth Factors FGF-2 and TGF 1: Synthesis, Characterization and Kinetic Modelling. Journal of Biomedical Nanotechnology, 2010, 6 (2), pp.106-116. 10.1166/jbn.2010.1102 . hal-03552182

\author{
HAL Id: hal-03552182 \\ https://hal.science/hal-03552182
}

Submitted on 2 Feb 2022

HAL is a multi-disciplinary open access archive for the deposit and dissemination of scientific research documents, whether they are published or not. The documents may come from teaching and research institutions in France or abroad, or from public or private research centers.
L'archive ouverte pluridisciplinaire HAL, est destinée au dépôt et à la diffusion de documents scientifiques de niveau recherche, publiés ou non, émanant des établissements d'enseignement et de recherche français ou étrangers, des laboratoires publics ou privés. 


\title{
Controlled Release Carriers of Growth Factors FGF-2 and TGF $\beta 1$ : Synthesis, Characterization and Kinetic Modelling
}

\author{
Nader Kalaji ${ }^{1}$, Alexander Deloge ${ }^{1}$, Nida Sheibat-Othman ${ }^{1, *}$, Olivier Boyron ${ }^{2}$, \\ Imad About ${ }^{3}$, and Hatem Fessi ${ }^{1}$ \\ ${ }^{1}$ Université de Lyon, Univ. Lyon 1, CNRS, CPE Lyon, UMR 5007, Laboratoire d'Automatisme et de Génie des \\ Procédés (LAGEP), 43 Bd du 11 Novembre 1918, F-69616 Villeurbanne, France \\ ${ }^{2}$ Université de Lyon, Univ. Lyon 1, CNRS, CPE Lyon, UMR 5265, Laboratoire de Chimie, Catalyse, Polyméres et \\ Procédés (C2P2), LCPP Team, 43 Bd du 11 Novembre 1918, F-69616, Villeurbanne, France \\ ${ }^{3}$ Laboratoire Interface Matrice Extracellulaire-Biomatériaux (IMEB), Faculté d'Odontologie, \\ Université de la Méditerranée, 27 Bd Jean Moulin, 13355 Marseille Cedex 05, France
}

\begin{abstract}
The purpose of this work is to produce microspheres loaded with transforming growth factor $\beta 1$ TGF $\beta 1$ and basic fibroblast growth factor FGF-2; to ensure the protein protection from degradation during the encapsulation and storage steps, to evaluate the release rate and the microspheres toxicity. The water in oil in water double emulsion technique was adapted to avoid the protein degradation during the encapsulation. The obtained microspheres were deeply characterized to evaluate their size, morphology, toxicity, the way of degradation, the protein stability and release rate. The microspheres were found to be biocompatible and the encapsulation efficiency was about $35 \%$. It was observed that the obtained microspheres increase the shelf life of the growth factors. The diffusion coefficient was quantified using Fick's law of diffusion that was combined to an empirical equation representing the decrease in the protein stability. Such modelling helped to give indirect information about the microspheres morphology and drug distribution within the microspheres. The main conclusion consists of the formation of a higher compact polymer matrix when smaller particles are produced, which has different distinct effects: the encapsulation efficiency and the stability of the encapsulated growth factor are enhanced while both the growth factor diffusion and the polymer degradation rates decrease.
\end{abstract}

Keywords: Polymers of Lactide and Glycolide, Growth Factors, Microencapsulation, Controlled Drug Release.

\section{INTRODUCTION}

Growth factors have a central role regulating a variety of cellular processes (proliferation, migration, differentiation...). Due to their short half life in solution, notable efforts were made to provide longer-term release of growth factors in tissue engineering and to ensure appropriate therapeutic concentrations. In a first approach, scaffolds, ${ }^{1}$ collagen sponge or agarose beads ${ }^{2}$ were directly impregnated with growth factors and applied for tissue regeneration. In a second approach, the growth factors were encapsulated in colloidal microspheres of micron size. ${ }^{3}$ Studies also reported microspheres embedded in a gel and used in a scaffolds system. ${ }^{1,4}$ In some cases, the microspheres were produced, sterilized then loaded with the growth factor and lyophilized. ${ }^{5}$ In this case, the growth factor is adsorbed on the polymer matrix. Encapsulation of growth factors ensures a better protection and controlled release than posterior incorporation to preformed spheres which provides a sustained effect. Advantages of using encapsulation methods are also related to the possibility of characterizing their physicochemical properties and relating them to the release rate.

A number of microencapsulation techniques have been developed and reported to date such as stimuli-responsive microgel containing protein, ${ }^{6}$ single emulsion process, ${ }^{7,8}$ double (multiple) emulsion process, phase separation (coacervation), spray drying ${ }^{9}$ and nanoprecipitation. ${ }^{10,11}$ 
The choice of the technique depends on the nature of the polymer, the drug, the intended use, and the duration of the therapy. Due to their hydrophilic nature, growth factors (also some proteins and peptides) are usually encapsulated by the water-in-oil-in-water (w/o/w) method followed by solvent extraction/evaporation. ${ }^{12-15}$ This microspheres fabrication procedure allows a better protection of the growth factor against degradation since it reduces the contact between the encapsulated agent and the organic solvent.

Protective biomaterials used for encapsulation of such drugs are mainly biodegradable natural polymers as dextrans, ${ }^{16}$ chitosan ${ }^{17}$ hyaluronic acid, and biodegradable synthetic polymers as polycaprolactone (PCL) ${ }^{18}$ and polymers of lactide and glycolide (PLGA). ${ }^{19}, 20$ PLA, PGA and their copolymers have been used to form both scaffolds and microspheres. The use of PLGA is approved by the U.S FDA. ${ }^{19}$ These copolymers have been used to prepare various drug loaded devices (vaccines, peptides, proteins and micromolecules) due to their excellent biocompatibility and biodegradability.

In this work, PLGA is used to encapsulate FGF-2 or TGF $\beta 1$ using the $w / \mathrm{o} / \mathrm{w}$ method. The produced microspheres were deeply characterized to investigate their toxicity, degradation rate of polymer, microspheres morphology, stability of the encapsulated drug, drug distribution, encapsulation efficiency, and the drug release rate. A mathematical law is used to describe the release rate. The combination of physical measurements and modelling estimations was found to be beneficial to investigate this system and interpret some observations.

\section{MATERIALS AND METHODS}

\subsection{Materials}

Poly (D,L lactic-co-glycolic acid) (PLGA) is RESOMER ${ }^{\circledR}$ RG $502 \mathrm{H}$ with a copolymer lactide-glycolide ratio of 48:52 to 52:48 was purchased from Boehringer Ingelheim. Recombinant Human Transforming Growth Factorbeta 1 (TGF $\beta 1)(25 \mathrm{KDa})$ was purchased from AbCys Company/France. Recombinant Human Fibroplast Growth factor FGF-2 (17 KDa) was kindly provided by Whenzhou Medical College/China. Albumin-fluorescin isothiocyanate conjugate bovine (FITC-BSA) $(60 \mathrm{kDa})$ was purchased from Sigma Chemical. Poly(vinyl alcohol) (PVA) was obtained from Fluka and Methylene chloride (DCM) from Carlo Erba Reagents. RayBio ${ }^{\circledR}$ Human
TGF $\beta 1$ and FGF-2 enzyme-linked immunosorbent assay (ELISA) Kit was purchased from BioCat/Germany. Cell culture medium used for stability and release studies was a serum-free DMEM (Gibco/France) supplemented with micokill and ciprofloxacin (Bayer/France).

\subsection{Preparation of Microspheres}

Microspheres of PLGA were prepared by the w/o/w double-emulsion and solvent extraction/evaporation method as previously described ${ }^{14,15}$ (Table I). PLGA was dissolved in DCM. This oil phase was then emulsified using a high speed mixing apparatus (Ultrathurrax ${ }^{\circledR}$, T25 basic, IKA ${ }^{\circledR}$ Werke/Germany) with an internal aqueous phase phosphate saline buffer (PBS) solution containing TGF $\beta 1$ or FGF-2 always with FITC-BSA to form a w/o emulsion. All preparations were performed at ambient temperature. The resulting emulsion was added to $50 \mathrm{~mL}$ of external aqueous solution containing $0.1 \%(\mathrm{w} / \mathrm{v})$ PVA and emulsified with Ultrathurrax ${ }^{\circledR}$ in order to produce the double w/o/w emulsion. The double emulsion was then poured into a large volume of water $(100 \mathrm{~mL})$ under magnetic stirring for 2.5 hours to allow removal of the organic solvent. Finally, the resulting microspheres were collected on a filter, washed twice with $50 \mathrm{~mL}$ of deionised water, dried and stored at $-20{ }^{\circ} \mathrm{C}$. Table II shows the different operating conditions considered to investigate the microspheres morphology.

The main precautions included in the previously developed w/o/w encapsulation method are:

-Double sterilized water was used in all solutions; beakers and glasses were sterilized; preparations take place under fume hood.

- Growth factors were stored at $-20{ }^{\circ} \mathrm{C}$; Growth factor solutions were prepared $10 \mathrm{~min}$ before the emulsion preparation.

- Stirring time of the first w/o emulsion was limited to $30 \mathrm{~s}$ to avoid heating.

-For solvent extraction, the final solution was poured into a large quantity of water under magnetic stirring without vacuum evaporation to avoid pressure aggression and temperature rising. Also, addition of isopropanol alcohol to accelerate solvent extraction was avoided.

-For protein extraction, Dimethyl sulfoxide (DMSO) was used to dissolve the microspheres, which is less aggressive than DCM used previously for PLGA dissolution. ${ }^{21,22}$

Table I. Conditions of the double emulsion method.

\begin{tabular}{|c|c|c|c|c|c|c|c|}
\hline $\begin{array}{l}\text { Growth } \\
\text { factor }\end{array}$ & Internal aqueous phase & Oil phase & $\begin{array}{l}\text { First emulsion } \\
\text { stirring time }\end{array}$ & $\begin{array}{l}\text { First emulsion } \\
\text { stirring speed }\end{array}$ & $\begin{array}{l}\text { External } \\
\text { aqueous phase }\end{array}$ & $\begin{array}{l}\text { Second emulsion } \\
\text { stirring time }\end{array}$ & $\begin{array}{l}\text { Second emulsion } \\
\text { stirring speed }\end{array}$ \\
\hline FGF-2 & $\begin{array}{l}\text { PBS solution containing } 1 \mathrm{mg} \\
\text { FITC-BSA and } 5 \mu \mathrm{g} \mathrm{FGF-2}\end{array}$ & $\begin{array}{l}2 \mathrm{~mL} \text { methylene } \\
\text { chloride containing } \\
500 \mathrm{mg} \text { PLGA }\end{array}$ & $30 \mathrm{~s}$ & $13000 \mathrm{rpm}$ & $0.1 \%(\mathrm{w} / \mathrm{v}) \mathrm{PVA}$ & $30 \mathrm{~s}$ & $6500 \mathrm{rpm}$ \\
\hline
\end{tabular}

TGF $\beta 1$ PBS solution containing $500 \mu \mathrm{g}$ FITC-BSA and $1.5 \mu \mathrm{g}$ TGF $\beta 1$ 
Table II. Conditions of the different experiments with the resulting microspheres size and encapsulation efficiency.

\begin{tabular}{|c|c|c|c|c|c|c|c|c|c|}
\hline Experiment & $\begin{array}{c}\text { Active } \\
\text { agent }\end{array}$ & $\begin{array}{c}\text { Internal aqueous } \\
\text { phase } \\
\text { volume }(\mu 1)\end{array}$ & $\begin{array}{l}\text { Water to } \\
\text { oil volume } \\
\text { ratios }\end{array}$ & $\begin{array}{c}\text { Second } \\
\text { emulsion } \\
\text { stirring speed }\end{array}$ & $\begin{array}{c}\text { Stirring } \\
\text { apparatus }\end{array}$ & $\begin{array}{l}\text { Size } \\
(\mu \mathrm{m})\end{array}$ & $\begin{array}{c}\text { Encapsulation } \\
\text { efficiency } \\
\text { Method } 1\end{array}$ & $\begin{array}{c}\text { Encapsulation } \\
\text { efficiency } \\
\text { Method } 2\end{array}$ & $\begin{array}{l}\text { Loading } \\
\text { ng/mg } \\
\text { (Method 1) }\end{array}$ \\
\hline $1 \mathrm{a}$ & FGF-2 & 250 & $1 / 2$ & 6500 & ULTRA-TURRAX $^{\circledR}$ & $8 \pm 5$ & 32 & 35.3 & 2.9 \\
\hline $1 b$ & TGF $\beta 1$ & & & & & $11 \pm 5$ & 33 & 36.3 & 1 \\
\hline $2 \mathrm{a}$ & FGF-2 & 100 & $1 / 5$ & & & $8 \pm 5.5$ & 32.4 & 35.3 & 2.9 \\
\hline $2 b$ & TGF $\beta 1$ & & & & & $11 \pm 5$ & 30.1 & 34.4 & 0.9 \\
\hline $3 a$ & FGF-2 & 25 & $1 / 10$ & & & $8 \pm 6.2$ & 31.3 & 35.3 & 2.8 \\
\hline $3 b$ & TGF $\beta 1$ & & & & & $11 \pm 5$ & 31.7 & 38.9 & 0.95 \\
\hline $4 a$ & FGF-2 & 100 & $1 / 5$ & 2000 & $\mathrm{Ika}^{\circledR}$ Mechanical Overhead & $93 \pm 25$ & 24.3 & 28. & 2.2 \\
\hline $4 b$ & TGF $\beta 1$ & & & & Stirrers & $137 \pm 40$ & 23.5 & 28.1 & 0.71 \\
\hline
\end{tabular}

\section{MICROSPHERES CHARACTERIZATION}

\subsection{Particle Size and Morphology}

Scanning electron microscopy (SEM) was performed using a FEG Hitachi ${ }^{\circledR}$ S 800 microscope. Microspheres were mounted onto metal stubs with a double sided adhesive tape, vacuum-dried, contacted with silver paint, sputtercoated with a thin layer of gold (10-150A) and imaged with the SEM at $15 \mathrm{kV}$ or $10 \mathrm{kV}$. The size distribution was determined with a laser diffraction technique using a Coulter ${ }^{\circledR}$ counter multisizer (Beckman Coulter LS 230) after dispersion of the microspheres in deionised water.

\subsection{Enzyme-Linked Immuno Sorbent Assay}

The titration of growth factors was performed using a human ELISA kit specific for each growth factor. $100 \mu \mathrm{L}$ of each sample solution were added into appropriate wells of the kit microtiter plate. After 2.5 hours of incubation at room temperature, the plate was rinsed several times with the kit buffer solution and a biotinyled antibody solution was added into each well and incubated for $1 \mathrm{~h}$. After washing away the unbound biotinylated antibody, a Streptavidine solution was added to the plates and incubated for $45 \mathrm{~min}$. The plates were finally washed five times and introduced into a luminescent plate reader (LabSystem). The light emission was recorded after the injection in each well of $150 \mu \mathrm{L}$ buffer containing $200 \mu \mathrm{M}$ of luminol, $500 \mu \mathrm{M}$ of hydrogen peroxide and $200 \mu \mathrm{M}$ of p-iodophenol. The calibration curves were generated for each growth factor with the appropriate kit standard solutions ranging from 0 to $100 \mathrm{ng} / \mathrm{mL}$.

\subsection{Encapsulation Efficiency and Drug Loading}

Two methods were used to measure the encapsulation efficiency. Method (1) consists of measuring the amount of growth factor entrapped in the microspheres after extraction (extraction protocol). The extraction protocol consists of dissolving about $20 \mathrm{mg}$ of microspheres in $1 \mathrm{~mL}$ of DMSO then adding $9 \mathrm{~mL}$ of cultural medium and analysing by ELISA. In Method (2), the encapsulation efficiency was calculated by deducting the lost quantity of growth factors in the aqueous supernatant at the end of the microspheres preparation (after solvent evaporation, before rinsing) from the initial used quantity.

\subsection{Protein Distribution into the Microspheres}

Protein distribution into the microspheres could be analyzed thanks to the presence of FITC-BSA in the microspheres, by confocal laser scanning microscopy (Leica Microsystems TCS SP2/Germany). The microspheres were suspended into water and spread on a cover slip. The fluorescein was excited by a $488 \mathrm{~nm}$ argon laser. Different sections of the microspheres were scanned. The images presented in this work were taken in a central section of the microspheres.

\subsection{Residual Solvent}

Gas chromatography was used to analyze the residual amount of DCM (Boiling point $(\mathrm{BP})=40^{\circ} \mathrm{C}$ ). An Agilent Model 4890 gas chromatograph was used with the program Star Chromatography Workstation and a BONDED FSOT Capillary column $30 \mathrm{~m} \times 0.53 \mathrm{~mm}$ (i.d.). The analytical conditions were: injector temperature $250{ }^{\circ} \mathrm{C}$; detector temperature, $280{ }^{\circ} \mathrm{C}$; initial oven temperature $70{ }^{\circ} \mathrm{C}$ that increased at $10{ }^{\circ} \mathrm{C} / \mathrm{min}$ to $220{ }^{\circ} \mathrm{C}$ with a final stabilization at this temperature for $2 \mathrm{~min}$ and flow rate of the carrier gas (nitrogen) was $13 \mathrm{~mL} / \mathrm{min}$. The calibration curve was based on different DCM concentrations in DMSO (500-31 ppm) with toluene as internal standard at a constant concentration of $100 \mathrm{ppm}$ then using the ratio of DCM to toluene areas under the peak. For the measurement of DCM residual amount in the microspheres, $50 \mathrm{mg}$ of microspheres were dissolved in $2 \mathrm{~mL}$ of DMSO $(\mathrm{BP}=$ $\left.189^{\circ} \mathrm{C}\right)$, an appropriate amount of toluene $\left(\mathrm{BP}=111^{\circ} \mathrm{C}\right)$ was added as an internal standard.

\subsection{PVA Content}

The residual amount of PVA in the microspheres was determined using an iodine-borate colorimetric method as proposed in Ref. [23] including some modifications proposed. ${ }^{7}$ The method requires the extraction of 
poly(vinyl alcohol) from the polymer matrix into the aqueous phase, followed by the formation of a PVAiodine-borate complex that can be detected by visible spectroscopy.

\subsection{Stability of Growth Factors in Aqueous Solution}

In order to study the growth factor stability in aqueous PBS solution ( $\mathrm{pH}=7.4)$ or in the culture medium (usually used for in vitro test on cultured cells), the same amount of growth factor (50 ng) was dissolved in flasks containing $1 \mathrm{~mL}$ solution. These flasks were put either at ambient temperature or in the refrigerator and the growth factor content was analyzed using ELISA.

\subsection{Microspheres Shelf Life}

The microcapsules shelf life, or the stability of encapsulated growth factors in the PLGA microsphere matrices, was studied as follows: Flasks of $20 \mathrm{mg}$ of microspheres were put at room temperature or at $5{ }^{\circ} \mathrm{C}$. The growth factor content was analyzed at specific intervals using ELISA by applying the extraction protocol explained above.

\subsection{Size Exclusion Chromatography (SEC)}

PLGA Degradation during the release was studied by monitoring the polymer molecular weight using Size Exclusion Chromatography (SEC). Waters SEC system was used. This system was equipped with an isocratic pump (Waters 515) operating at a flow-rate of tetrahydrofuran (THF) of $1 \mathrm{~mL} / \mathrm{min}$, a refractive-index detector Model (Waters 410) with integrated temperature controller to maintain temperature at $35{ }^{\circ} \mathrm{C}$, a guard column (PLgel $5 \mu \mathrm{m}$ ) and three Polymer Laboratories columns $(2 \times$ PLgel $5 \mu \mathrm{m}$ Mixed C $(300 \times 7.5 \mathrm{~mm})$ and 1 PLgel $5 \mu \mathrm{m} 500 \mathrm{~A}(300 \times 7.5 \mathrm{~mm}))$, all columns working in-line and the software Empower pro. The calibration was carried out using narrow distributed polystyrene standards. After specific time intervals of suspension in PBS, the microspheres were collected and vacuum dried for $24 \mathrm{~h}$ to determine the PLGA molecular weight. Samples of microspheres were dissolved in THF and put in an ultrasonic bath to obtain a homogenous solution. Chromatography was carried out after sample filtration using a $0.45 \mu \mathrm{m}$ filter.

\subsection{Microspheres Morphology Alteration}

The morphology of the microspheres was assessed by SEM and the evolution in the surface properties of the microspheres was analysed by atomic force microscopy (AFM) after specific intervals of suspension in water. For AFM analysis, after suspension in distilled water, the microspheres were taken and deposited on freshly cleaved muscovite mica. The still wet sample was observed at room temperature on a multimode-Veeco AFM in tapping mode.

\subsection{In Vitro Release Study}

Known quantities of microspheres were dispersed in test tubes containing $1 \mathrm{~mL}$ of culture medium. The suspension was gently stirred at room temperature. At specific intervals, the tubes were centrifuged at a rotating rate of $14000 \mathrm{rpm}$ for $10 \mathrm{~min}$ and analyzed by ELISA.

\section{RESULTS}

\subsection{Microspheres Size and Morphology}

As usually observed in the double emulsion method, ${ }^{14,15,21,22}$ a broad size distribution was obtained for formulations containing TGF $\beta 1$ or FGF-2 (Table II). Figure 1 shows that the obtained microspheres are quite spherical and have a smooth and regular surface as observed by SEM and confirms the polydispersity of the microspheres.

The water-to-oil volume ratio in the internal emulsion had no effect on the particle size as previously shown. ${ }^{15,21}$ The stirring speed, on the contrary, had a significant effect on the microspheres size that varies from about 90 to $8 \mu \mathrm{m}$ with stirring speeds of 2000 and $6500 \mathrm{rpm}$.

\subsection{Encapsulation Efficiency and Drug Loading}

Using the method referred as the extraction protocol, the encapsulation efficiency was $32 \%$ for small microspheres and $24 \%$ for big ones for both growth factors (Table II). The second method consisting of dosing the growth factor lost in supernatant after collecting the microspheres estimates the encapsulation efficiency between

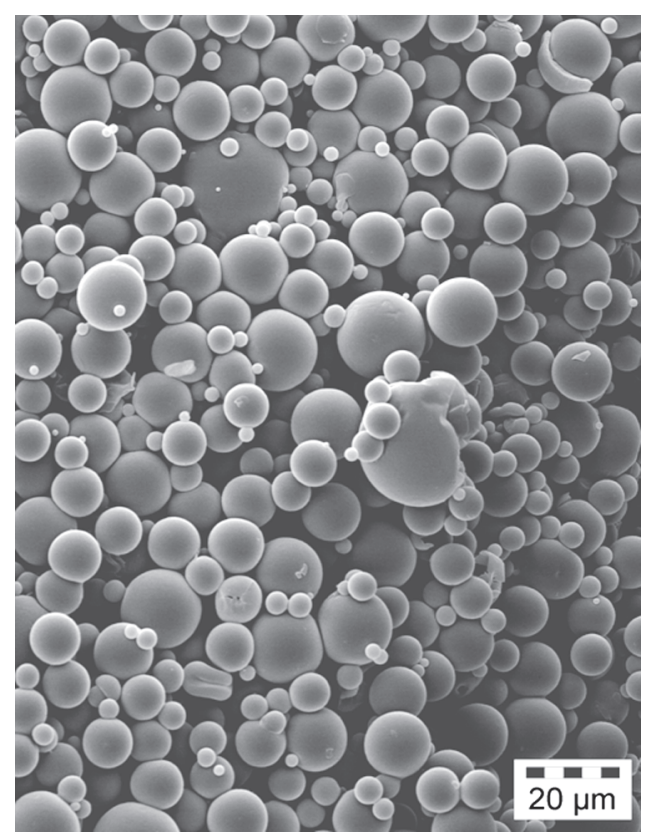

Fig. 1. SEM pictures of PLGA microspheres (experiment 2a). 
$35 \%$ and $39 \%$ for small microspheres and approximately $28 \%$ for big ones. The difference between both methods can be explained by the reduction of the growth factor activity due to contact with solvent or water. On one hand, during the extraction protocol, the contact with DMSO might reduce the growth factor stability which misestimates the real loading of microspheres. On the other hand, the activity of growth factor present in the aqueous supernatant might decrease and hence the calculation leads to overestimating the real growth factor loading.

From these data, growth factors loading into the microspheres could be calculated and was found to be equal to $2.9 \mathrm{ng} / \mathrm{mg}$ for FGF-2 and approximately $1 \mathrm{ng} / \mathrm{mg}$ for TGF $\beta 1$.

\subsection{Protein Distribution within the Microspheres}

FITC-BSA was incorporated into the microspheres together with the growth factors. The fluorescence of the albumin allows the detection of FITC-BSA in the microspheres using fluorescence confocal microscopy. The distribution of FITC-BSA in the microspheres should be comparable to that of the growth factors, but not necessarily the encapsulation efficiencies. Confocal microscopic images show a homogeneous distribution of the FITC-BSA in the microspheres at $30 \mathrm{~min}$ with a slightly higher density near to the surface and in the central part (Fig. 2(a)). The centre contains no FITC-BSA after 1 day (Fig. 2(b)) and after 7 days, FITC-BSA is mainly present in the periphery (Fig. 2(c)). This suggests a gradual diffusion of FITC-BSA through the microsphere with time.

\subsection{Residual Solvent}

Residual DCM level in the microspheres as determined by GC was always about $3 \mathrm{ppm}$ of DCM per $\mathrm{mg}$ of microspheres (about $150 \mathrm{ppm}$ of DCM in $50 \mathrm{mg}$ of microspheres).

\subsection{PVA Content}

Blank samples (not containing protein or growth factors) were previously analyzed ${ }^{14}$ for the PVA content before and after double rinsing and it was found that rinsing allows eliminating most of the PVA. In this work, after rinsing, $0.5 \%$ by weight of PVA was found in the microspheres. Similar results were reported in the literature. ${ }^{9,23}$

\subsection{Growth Factors Stability in Aqueous Solution}

The stability of FGF- 2 and TGF $\beta 1$ in PBS buffer (pH 7.4) or in the culture medium was measured by ELISA. The decrease of FGF- 2 and TGF $\beta 1$ concentration with time in the PBS buffer was very fast (Fig. 3). On the other side, growth factors stability in culture medium was very good. Figure 4 shows only FGF-2 stability. Similar results were found for TGF $\beta 1$ (data not shown).

\subsection{Microspheres Shelf Life}

Figures 5 and 6 show that the decrease in the activity of encapsulated growth factors is much lower than free growth factor in the aqueous medium which means that the

(a)

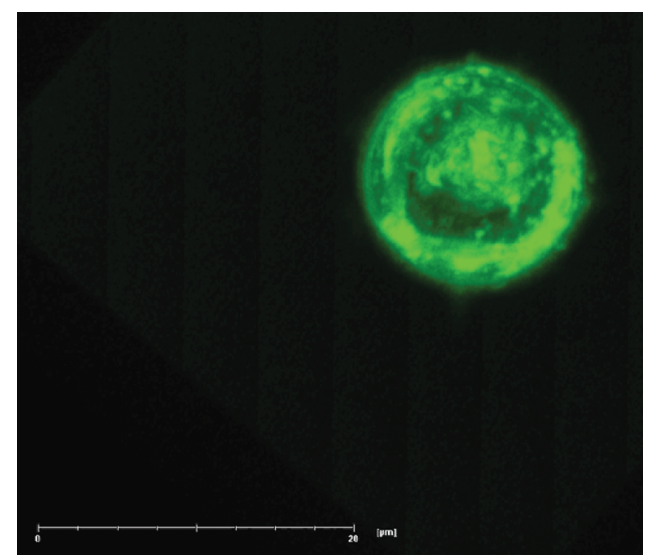

(b)

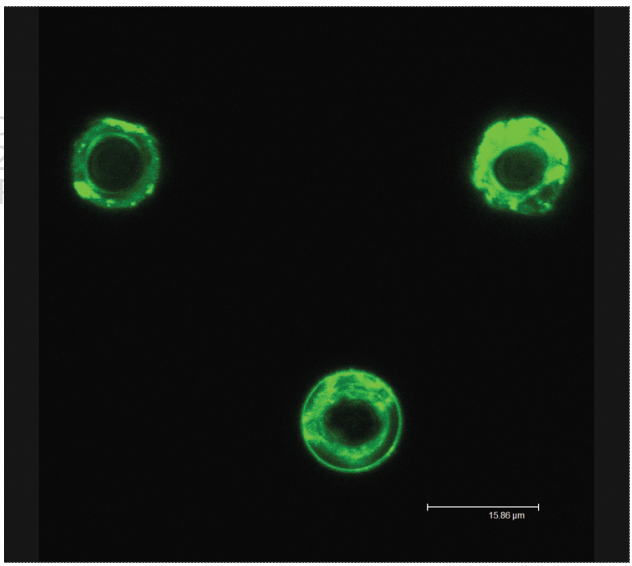

(c)

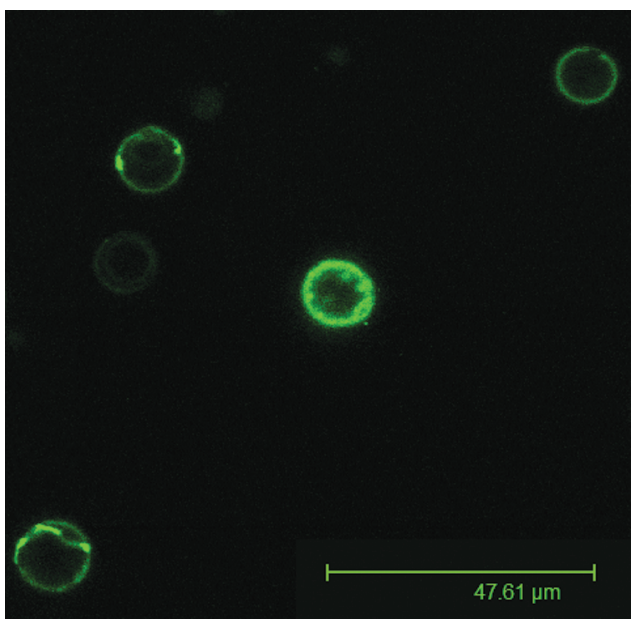

Fig. 2. Confocal microscopy micrographs (central section). The distribution of FITC-BSA within the microspheres after (a) 30 minutes, (b) 1 day and (c) 7 days. 
Decrease in FGF-2 activity in PBS

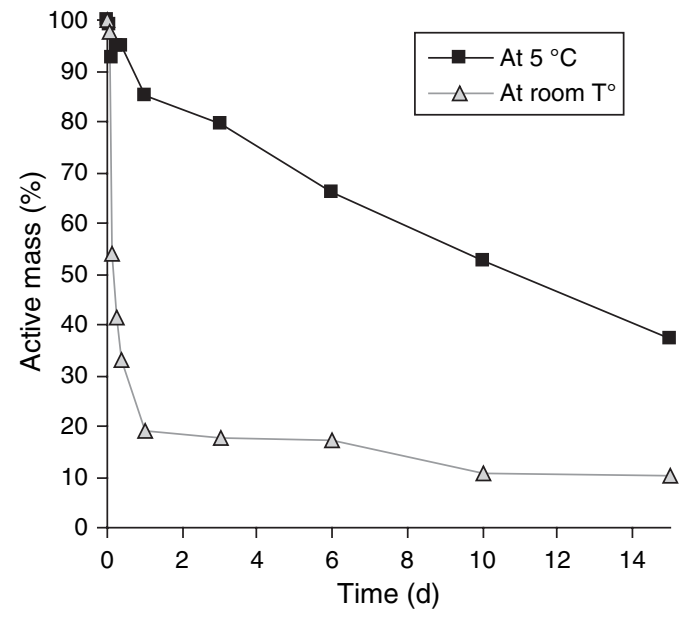

Decrease in TGFß1 activity in PBS at room $\mathrm{T}^{\circ}$

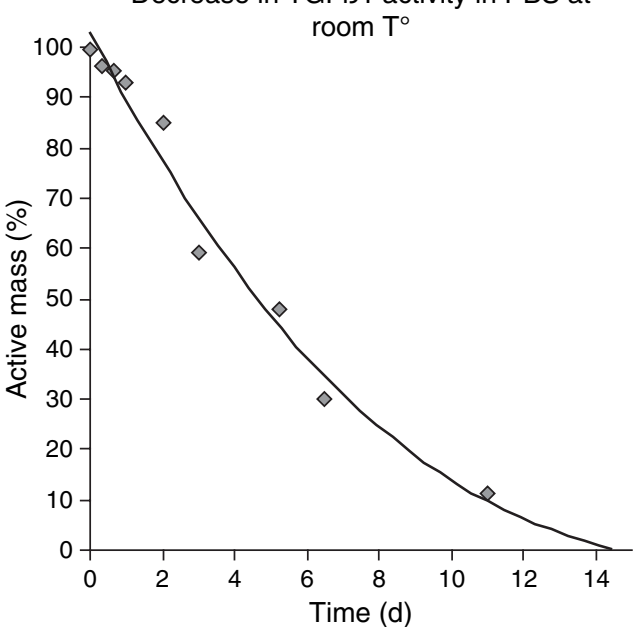

Fig. 3. Decrease in the activity of both growth factors in PBS, very fast decrease is shown at room temperature for both growth factors. At $5^{\circ}$ slower decrease was remarked but is still fast comparing with culture medium.

polymeric membrane enhances the stability of the growth factor. It is interesting here to investigate the temperature effect and the microspheres size and permeability on the encapsulated growth factor stability. Figure 5 shows, as expected, that loading decreases more rapidly at higher temperature. It is interesting to notice also that the shelf life of big microspheres loaded with FGF-2 is somewhat shorter than smaller microspheres.

Figure 6 shows that after 21 days, the microspheres shelf life is proportional to the w/o ratio in the internal phase (for TGF $\beta 1$ a slight effect of internal ratio was found after only 6 days). A more compact microsphere (lower w/o internal ratio) leads to an improved protection of the growth factor.

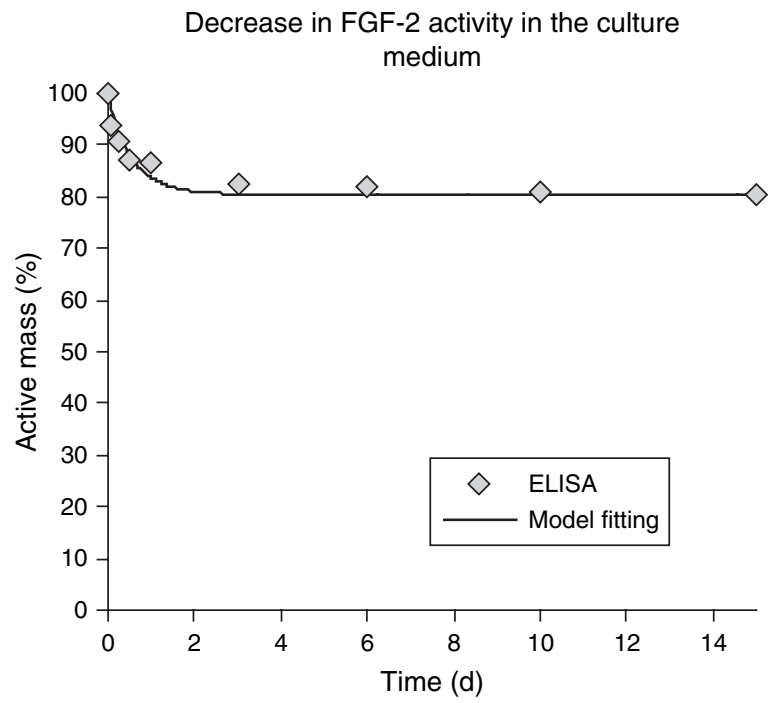

Fig. 4. Decrease of the activity of FGF-2 in culture medium at room temperature. The protein degradation rate coefficient represents the aggression of the medium. This coefficient was fitted using the ELISA data to be $k=6.6 e-4 n g^{-1} \cdot h^{-1}$.

\subsection{Microspheres Degradation}

From the microspheres SEM pictures (Fig. 7), it can be seen that the spherical shape of the microspheres is deformed with time and surface irregularities appear with some pores on the surface and even some exploded microspheres can be detected.

Microspheres surface morphology observed by AFM microscopy after 30 days in water reveals a soft microsphere with a rough and irregular surface and confirms the loss of surface smoothness (Fig. 8).

SEC measurements (Fig. 9) show a slight decrease in the PLGA molecular weight during the contact with water.

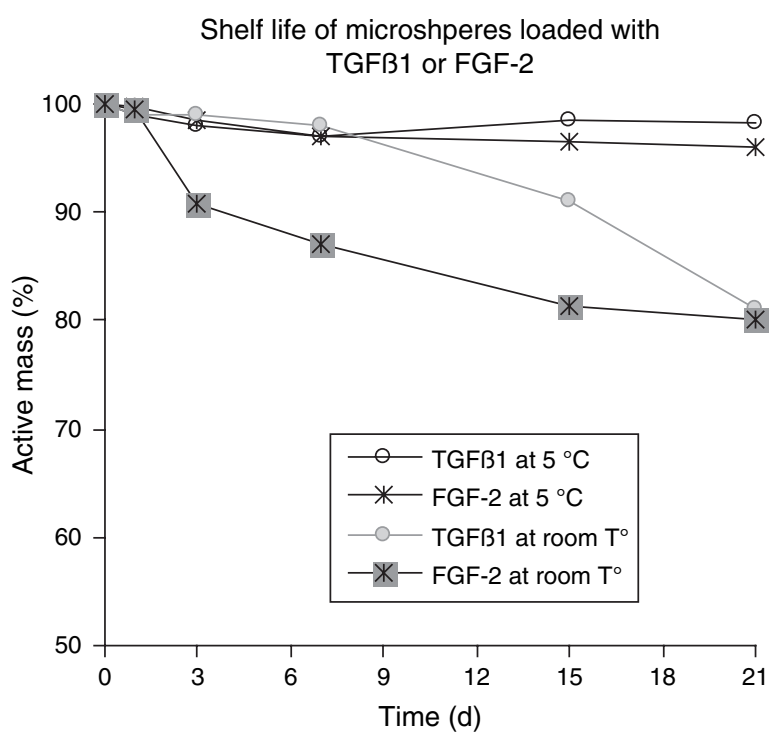

Fig. 5. Shelf life of FGF-2-loaded microspheres as a function of the particle size and temperature (w/o internal ratio $=1 / 5$ ). The loading decreases more rapidly at higher temperature. The shelf life of big microspheres loaded with FGF-2 is shorter than smaller microspheres. 

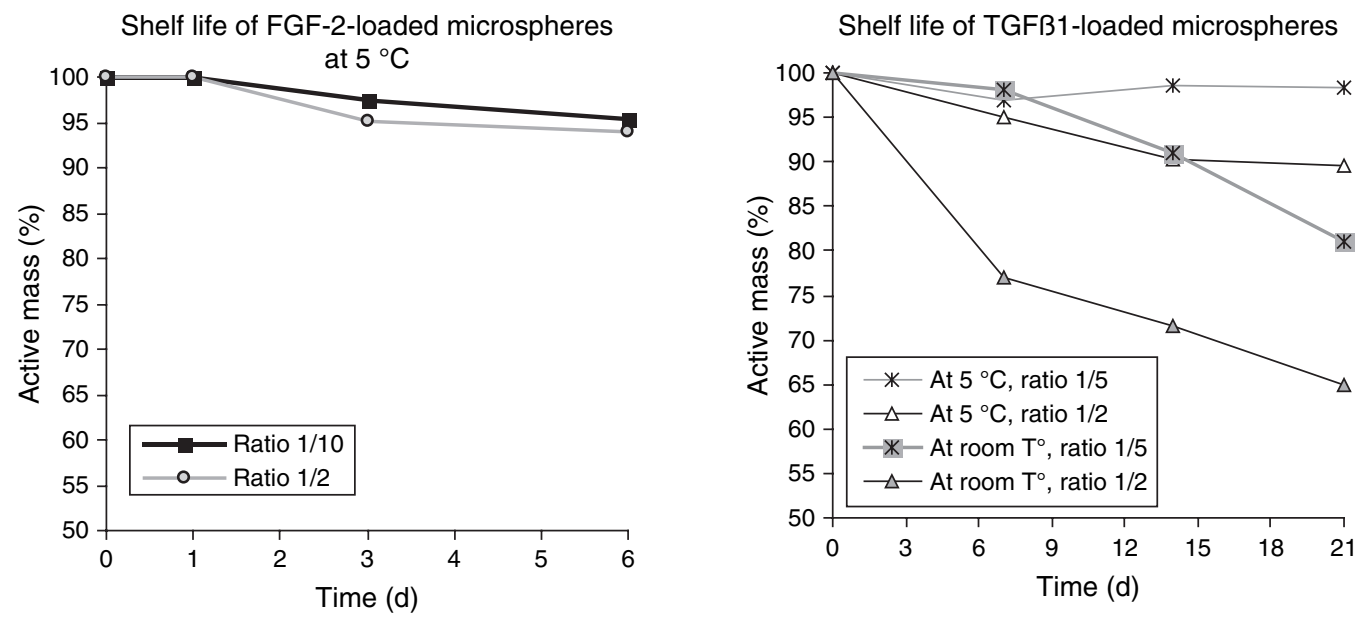

Fig. 6. Shelf life of small microspheres as a function of the internal w/o ratio for both growth factors. A very slight effect was found in the first 6 days as seen for TGF $\beta 1$. A significant effect of internal ratio was found after 21 days as seen for FGF-2.

This decrease is (partly) responsible of the polymeric matrix erosion and should affect the growth factors diffusion in the matrix and therefore the release rate.

\subsection{In Vitro Release Study}

The release kinetics showed the existence of a phase of rapid release during the first 24 hours in which about $30-56 \%$ of the drug is released (Figs. 10-11). This phenomenon is described in the literature as the burst effect and can be beneficial in order to ensure the therapeutic dose (see for instance Ref. [4]). This phenomenon can be due to the non homogeneity of the matrix that contains big and small cavities. Bigger cavities might be formed preferably close to the microspheres surface due to violent solvent extraction. Diffusion out of big cavities is rapid and therefore comes quickly to end while diffusion through very small cavities is lower and continue for a longer period of time.

Figure 10 compares the amount of FGF-2 released with time as a function of the microspheres size. It can be seen that almost the same amount is released from both small and big microspheres. Since small microspheres have a higher contact surface area with the release medium, then it can be concluded that the diffusion coefficient of small microspheres is lower than bigger ones.

The effect of the internal w/o ratio on the diffusion rate can be observed on Figure 10. It can be seen that the released amount of drug is proportional to the internal w/o ratio. Since the internal w/o ratio had no effect on the particle size as reported previously by our team, ${ }^{15}$ then it can be concluded that a higher diffusion coefficient is obtained for higher internal w/o ratio.

\subsection{Estimation of the Diffusion Coefficient}

The second Fick's law of diffusion ${ }^{32}$ was used to estimate the diffusion coefficient. In spherical particles, an analytical solution of this law can be derived assuming homogeneous dispersion of the drug in the sphere, constant diffusion coefficient on the particle radius $(r)$ perfect
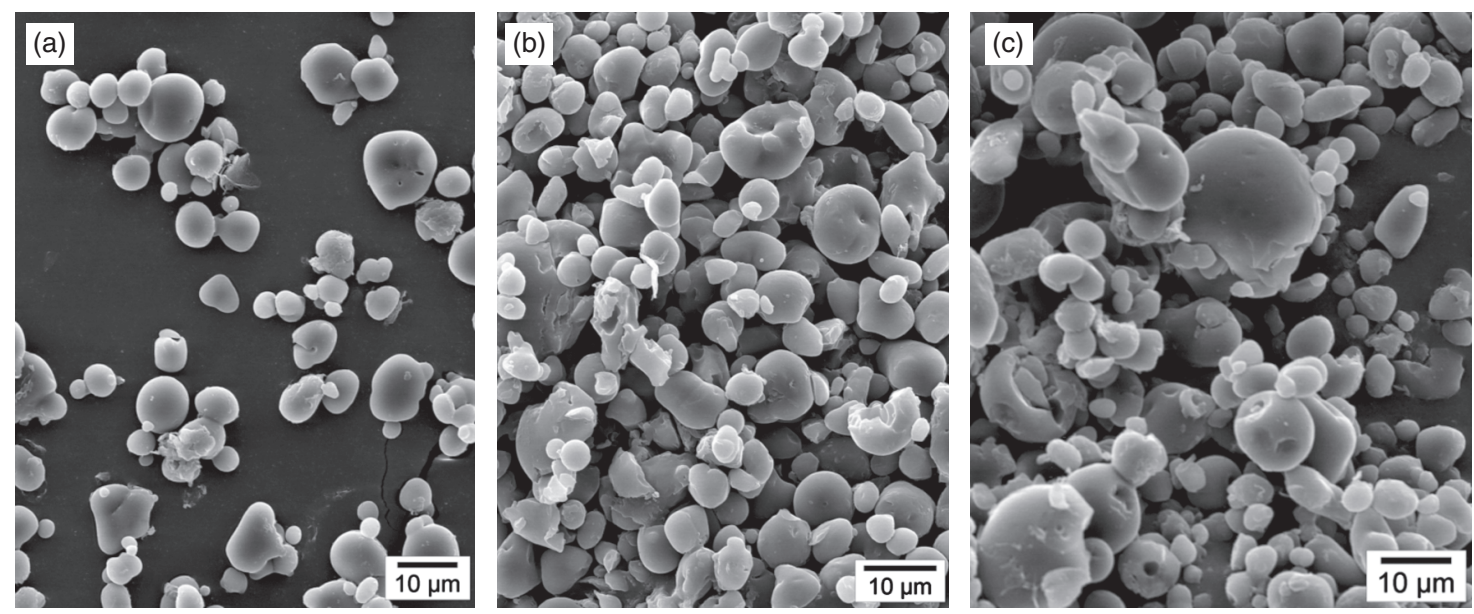

Fig. 7. SEM pictures showing the degradation of the microsphere after (a) 7 days, (b) 14 days and (c) 30 days of suspension in PBS. 


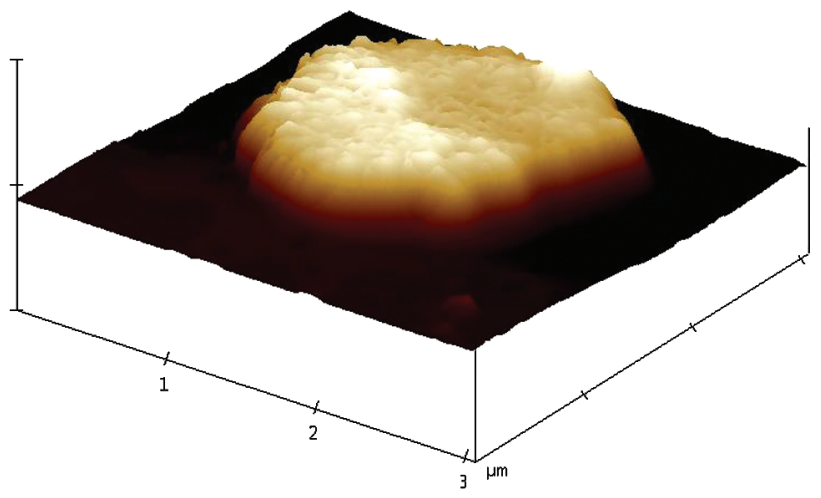

Fig. 8. Microspheres surface morphology by AFM after 30 days in water.

sink conditions and a drug loading that is lower than the solubility of the drug inside the polymer matrix:

$$
\frac{M_{t}}{M_{\infty}}=1-\frac{6}{\pi^{2}} \sum_{n=1}^{\infty} \frac{1}{n^{2}} \exp \left(\frac{-D n^{2} \pi^{2} t}{r^{2}}\right)
$$

where $M_{t}$ and $M_{\infty}$ are the cumulative absolute amounts of the drug released at time $t$ and at infinite time respectively, $r(\mu \mathrm{m})$ is the average microspheres size and $D\left(\mu \mathrm{m}^{2} / \mathrm{s}\right)$ is the apparent diffusion coefficient.

In order to take in account the stability of released growth factors in the culture medium, we consider data given in Figure 4. It can be seen that the decrease in the growth factor activity is rapid at the beginning but almost stops after few days. Protein degradation is a complex domain that involves different chemical and physical pathways. The decrease in the protein activity in the release medium due to interactions with this medium (depending on the type of solvent, temperature, $\mathrm{pH}$, presence of protective excipients ...) is represented by superficial amount of the protein $(X)$. The reduction in the growth factors

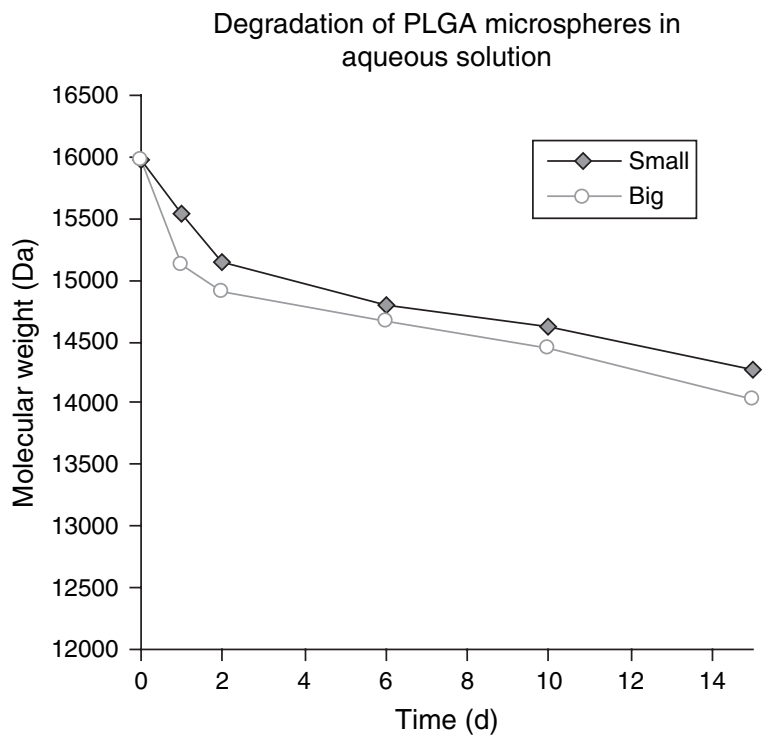

Fig. 9. Degradation of the polymer matrix measured by SEC. activity in water and in the culture medium can mathematically be represented by the following system:

$$
\left\{\begin{array}{l}
\frac{d M_{t}}{d t}=\underbrace{\Delta M_{t \_ \text {released }}}_{\text {Input due to release }}-\underbrace{k M_{t} X}_{\text {Output due to degradation }} \\
\frac{d X}{d t}=-k M_{t} X
\end{array}\right.
$$

Where $M_{t}$ is the protein mass and $k$ is the protein degradation rate coefficient (Fig. 4). This unique coefficient represents the aggression of the considered medium. This coefficient was fitted using the ELISA data to be $k=$ $6.6 e-4 \mathrm{ng}^{-1} \cdot h^{-1}$. In this model, the initial value of $X(\mathrm{ng})$ is the amount of $M_{t}$ to be denatured in the considered medium. When $X$ is totally consumed, $M_{t}$ becomes stable. In Eq. (2), $\Delta M_{t_{-} \text {released }}=$ the released amount of drug during the sampling period.

In order to estimate the diffusion coefficient, one has to take in consideration the diffusion rate of the drug and the reduction in its activity simultaneously (Eqs. (1) and (2)). An optimization example is shown on Figure 11. The figure shows the released and residual amounts of growth factor obtained with the optimized diffusion coefficient. It can be seen when comparing the curves referred to as 'Released' and 'Residual' that an important amount of the drug is degraded during the release study. In these curves, a time-constant diffusion coefficient is considered (Table III) which assumes that the matrix porosity is homogeneous. However, the occurrence of a burst effect reveals some heterogeneity in the matrix (presence of small and big cavities) which leads to a variation in $D$ with time. Therefore, the same optimization method explained above was applied by authorizing $D$ to vary with time. Actually, optimization is done over 3 data measurements at a time. Then, the optimization recedes by ignoring the oldest data point and adding a new point at the right hand side of the figure and so on. The released and residual curves obtained by the receding horizon optimization are shown on Figure 11 and referred to as 'adaptive'. It can be seen that a more precise fitting is obtained in this case. The time-varying estimated diffusion coefficients as obtained by the adaptive method are shown on Figure 11. It can be seen that $D$ decreases with time. It is important to remind that the molecular weight of polymer slightly decreased with time which could increase the diffusion rate, but this was not the case, therefore it was not necessary to incorporate degradation of the polymer molecular weight in the model.

The time-constant diffusion coefficients estimated in these experiments are shown in Table III. The table confirms our expectations regarding the size effect and the internal w/o ratio on the diffusion coefficient. It can be seen that the diffusion coefficient increases with increasing the internal w/o ratio which increases the microspheres 

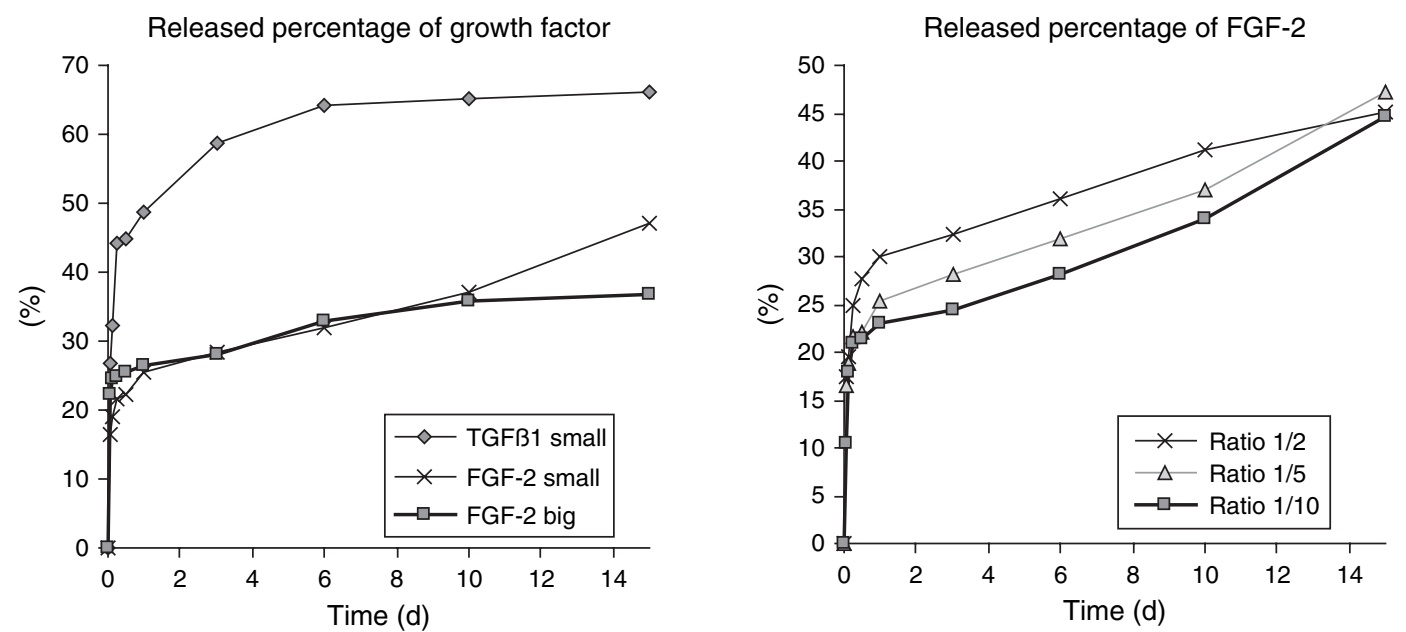

Fig. 10. Release profile of FGF-2- and TGF $\beta 1$-charged microspheres as a function of the microspheres size and w/o ratio in the internal phase.
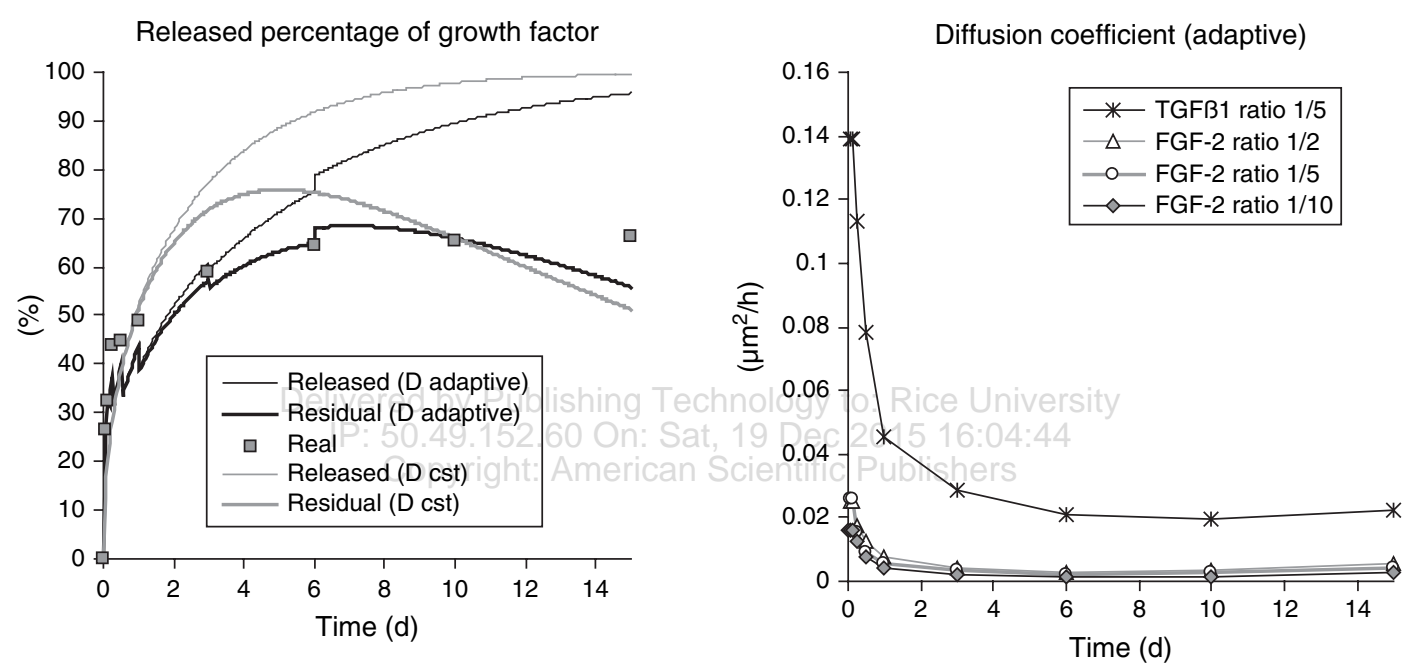

Fig. 11. At left, identification of $D$ in experiment 2b. At right: Estimation of $D$ by using receding horizon optimization for small microspheres $(D$ of experiment $4 \mathrm{a}$, bigger microspheres, goes from 6 to $0.3 \mathrm{ng}^{2} / \mathrm{h}$ ). Adaptive refers to a receding horizon optimization (varying $D$ ), otherwise $D$ is constant.

porosity. It can also be seen that the diffusion coefficient of small particles is much lower than that of bigger ones. Finally, the diffusion coefficient of TGF $\beta 1$ (25 KDa) (microspheres size $\approx 137 \mu \mathrm{m}$ ) is higher than that of FGF-2 (17 KDa) (microspheres size $\approx 93 \mu \mathrm{m}$ ). The release rate difference should mainly be due to differences in the molecular nature between these growth factors, since differences in the size are negligible. When comparing to the diffusion coefficient of bovine serum albumin (BSA) (fraction

Table III. Estimation of the diffusion coefficient.

\begin{tabular}{lc}
\hline $\begin{array}{l}\text { Experimental conditions (a stands } \\
\text { for FGF-2 and b for TGF } \beta \text { 1) }\end{array}$ & $\begin{array}{c}\text { Average diffusion coefficient } \\
\left(\mu \mathrm{m}^{2} / \mathrm{h}\right)\end{array}$ \\
\hline 1a (Small microspheres, ratio 1/2) & 0.0053 \\
2a (Small microspheres, ratio 1/5) & 0.0039 \\
3a (Small microspheres, ratio 1/10) & 0.0027 \\
4a (Big microspheres, ratio 1/5) & 0.5469 \\
2b (Small microspheres, ratio $1 / 5)$ & 0.0424 \\
\hline
\end{tabular}

$\mathrm{V}, 60 \mathrm{kDa}$ ) estimated previously, ${ }^{15}$ it could be seen that the diffusion coefficient was 1000 times higher for BSA than FGF-2 for both big and small particles.

\section{DISCUSSION}

Spherical microspheres with a smooth surface were formed by the proposed method. Dependence of the microsphere size on the stirring energy was confirmed. Concerning the microspheres biocompatibility, it was evaluated by measuring the residual solvent and surfactant concentrations. Indeed, DCM is an organic solvent that can be dangerous for humans when inhaled at a high concentration and was found to cause cancer in humans exposed to vapours in the workplace. ${ }^{24}$ Studies of Serota et al. recommends that exposure of children to DCM be limited to less than $5 \mathrm{mg} / \mathrm{L}$ of drinking water for 1 day. ${ }^{24,25} \mathrm{In}$ the produced microspheres, DCM concentration was about 
3 ppm per mg of microspheres, which allows the administration of several milligrams of microspheres without any risk. The PVA concentration was about $0.5 \%$ by weight. This concentration is also lower than the potential toxic dose. ${ }^{26}$ The obtained microspheres loading $(2.9 \mathrm{ng} / \mathrm{mg}$ for FGF- 2 and $1 \mathrm{ng} / \mathrm{mg}$ for TGF $\beta 1$ ) is appropriate for local applications since the therapeutic doses of growth factors are usually between 10 and $20 \mathrm{mg}$ of microspheres. ${ }^{27-31}$ The produced microspheres are therefore adequate for human use.

It can be confirmed that the polymeric membrane enhances the stability of the growth factor. The shelf life of the growth factor-loaded microspheres is much higher than solutions of these growth factors. At ambient temperature, more than $80 \%$ of growth factor in water solution was lost in 15 days. Only $20 \%$ of encapsulated growth factor was lost after 15 days at ambient temperature. In the other side, storing microspheres in freezer keep them entirely actives.

Since the produced microspheres are designated for dentin-pulp complex regeneration, the release study was done in a culture medium that is usually used for in vitro tests on cultured cells. Even though confocal microscopic images show a homogeneous distribution of the FITCBSA in the microspheres and a gradual diffusion of FITC-BSA through the microsphere with time, a burst effect took place in this system which should be due to the presence of different sizes of cavities in the microspheres as previously shown by SEM. ${ }^{15}$ The effect of alterations in the microspheres morphology and degradation of the polymer molecular weight on the protein diffusion coefficient can be supposed to be negligible during the considered period of time as supported by mathematical modelling and SEM and SEC analysis.

It is observed that the production of smaller microspheres has several beneficial effects. First of all, the encapsulation efficiency is higher in smaller microspheres. Second, the shelf life of small microspheres loaded with FGF-2 is somewhat longer than bigger microspheres. Third, the polymer molecular weight of microspheres suspended in aqueous solution decreases less rapidly in smaller microspheres even though their surface area is bigger. Fourth, the diffusion rate coefficient is lower in smaller microspheres. The explanation for these observations can be the following: during the formulation process, for small microspheres the polymeric precipitation is done more rapidly protecting thereby a higher amount of growth factor than bigger ones. It seems also that a higher compact polymer matrix is formed if polymeric precipitation is rapid which prevents explosion of the primary cavities. By this way, the protein diffusion coefficient out of the microspheres is lower in smaller microspheres. Water diffusion into the microspheres should also be slower and therefore the degradation of the polymer molecular weight is slower in smaller microspheres. Finally, the stability of the protein in smaller microspheres is enhanced due to the higher permeability ensured by the compact matrix.

\section{CONCLUSIONS}

FGF-2 and TGF $\beta$ 1-loaded microspheres were prepared, characterized and their release profile was examined. The developed method was found to be adapted to growth factors encapsulation and leaded to an encapsulation efficiency of about $35 \%$. Microspheres' loading is adequate for therapeutic applications. The obtained microspheres have no potential toxicity regarding the PVA and solvent content. The microspheres enhance the stability of the growth factors and ensure controlled release. The activity of the encapsulated growth factor was conserved and the microspheres were found to be biocompatible and adapted for tissue engineering.

The internal morphology of the microspheres was found to be related to the precipitation time of the polymer. Smaller microspheres are supposed to precipitate faster due to their higher surface area. It was found that smaller microspheres have a higher compact matrix. Indeed, the drug stability is enhanced in smaller microspheres. The degradation rate of the polymer molecular weight of smaller microspheres is lower than bigger ones and the diffusion coefficient of smaller particles is much lower than bigger ones. Note that this last comment does not mean that diffusion rate out of smaller microspheres is lower than bigger ones since their surface area is higher. Added to all these advantages of smaller microspheres, their encapsulation efficiency is also higher than bigger ones. Therefore, fabrication of small microspheres is recommended to have optimized microspheres characterizations such as low release rate and high drug stability.

It is amazing to see that combination of some characterization and process modelling could give information about the internal morphology of the microspheres while small microspheres could not be easily cut into parts to be observed by microscopy as done for bigger microspheres. ${ }^{15}$

Acknowledgment: The authors would like to thank professor Li from Whenzhou Medical College (Chashan Gaojiao Yuanqu, Whenzou, China) for the supply with Fibroblast Growth Factor. The authors would like to thank also Professor Hassan Saadaoui from Centre de Recherche Paul Pascal (Pessac, France) for his kind help in AFM microscopy study.

\section{References and Notes}

1. H. D. Kim and R. F. Valentini, Retention and activity of BMP-2 in hyaluronic acid-based scaffolds in vitro. J. Biomed. Mater. Res. B 59, 573 (2001). 
2. N. Six, J. J. Lasfargues, and M. Goldberg, Differential repair responses in the coronal and radicular areas of the exposed rat molar pulp induced by recombinant human bone morphogenetic protein 7 (osteogenic protein 1). Arch. Oral. Biol. 47, 177 (2002).

3. E. K. Moioli, L. Hong, J. Guardado, P. A. Clark, and J. J. Mao, Sustained release of TGF $\beta 3$ from PLGA microspheres and its effect on early osteogenic differentiation of human mesenchymal stem cells. Tissue Eng. 12, 537 (2006).

4. S. E. Kim, J. H. Park, Y. W. Cho, H. Chung, S. Y. Jeong, E. B. Lee, and I. C. Kwon, Porous chitosan scaffold containing microspheres loaded with transforming growth factor- $\beta$ : Implications for cartilage tissue engineering. J. Control Release 91, 365 (2003).

5. W. Zhang, X. F. Walboomers, and J. A. Jansen, The formation of tertiary dentin after pulp capping with a calcium phosphate cement, loaded with PLGA microparticles containing TGF- $\beta$ 1. J. Biomed. Mater. Res. 58A, 439 (2007).

6. C. Yan, A. Elaissari, and C. Pichot, Loading and release studies of proteins using poly(N-isopropylacrylamide) based nanogels. J. Biomed. Nanotechnol. 2, 208 (2006).

7. M. Hamoudeh, A. Al. Faraj, E. Canet-Soulas, F. Bessueille, D. Leonard, and H. Fessi, Elaboration of PLLA-based superparamagnetic nanoparticles: Characterization, magnetic behaviour study and in vitro relaxivity evaluation. Int. J. Pharm. 338, 248 (2007).

8. S. Murugesan, S. Ganesan, R. K. Averineni, M. Nahar, P. Mishra, and N. Kumar, PEGylated poly(lactide-co-glycolide) (PLGA) nanoparticulate delivery of docetaxel: Synthesis of diblock copolymers, optimization of preparation variables on formulation characteristics and in vitro release studies. J. Biomed. Nanotechnol. 3, 52 (2007).

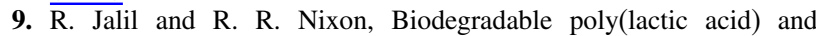
poly(lactide-co-glycolide) microcapsules: Problems associated with preparative techniques and release properties. J. Microencapsul. 7, $297(\mathbf{1 9 9 0 )}$.

10. H. Fessi, F. Puisieux, J. Ph. Devissaguet, N. Ammoury, and S. Benita, Nanocapsule formation by interfacial polymer deposition following solvent displacement. Int. J. Pharm. 55, R1 (1989).

11. K. Bouchmila, S. Briançon, E. Perrier, and H. Fessi, Nano-emulsion formulation using spontaneous emulsification: Solvent, oil and surfactant optimisation. Int. J. Pharm. 280, 241 (2004).

12. H. Jeffery, S. S. Davis, and D. T. O'Hagan, The preparation and characterisation of poly(lactide-co-glycolide) microparticles. II. The entrapment of a model protein using a (water-in-oil)-in-water emulsion solvent evaporation technique. Pharm. Res. 10, 362 (1993).

13. Y. Ogawa, M. Yamamoto, H. Okada, T. Yashiki, and T. Shimamoto, A new technique to esciently entrap leuprolide acetate into microcapsules of polylactic acid or copoly(lactic/glycolic) acid. Chem. Pharm. Bull. 36, 1095 (1988).

14. N. Kalaji, N. Sheibat-Othman, H. Saadaoui, A. Elaissari, and H. Fessi, Colloidal and physicochemical characterization of proteincontaining PLGA microspheres before and after drying. E-polymers 10, ISSN 1618-7229 (2009).

15. A. Deloge, N. Kalaji, N. Sheibat-Othman, V. S. Lin, P. Farge, and H. Fessi, Investigation of the preparation conditions on the morphology and release kinetics of biodegradable particles: A mathematical approach. J. Nanosci. Nanotechnol. 8, 1 (2009).

16. F. M. Chen, Y. M. Zhao, H. H. Sun, T. Jin, Q. T. Wang, W. Zhou, Z. F. Wu, and Y. Jin, Novel glycidyl methacrylated dextran (DexGMA)/gelatin hydrogel scaffolds containing microspheres loaded with bone morphogenetic proteins: Formulation and characteristics. J. Control Release 118, 65 (2007).
17. X. Niu, Q. Feng, M. Wang, X. Guo, and Q. Zheng, Preparation and characterization of chitosan microspheres for controlled release of synthetic oligopeptide derived from BMP-2. J. Microencapsul. 26, 297 (2009).

18. R. Diab, M. Hamoudeh, O. Boyron, A. Elaissari, and H. Fessi, Microencapsulation of cytarabine using poly(ethylene glycol)poly(epsilon-caprolactone) diblock copolymers as surfactant agents. Drug. Dev. Ind. Pharm. 36, 456 (2010).

19. R. A. Jain, The manufacturing techniques of various drug loaded biodegradable poly(lactide-co-glycolide) (PLGA) devices. Biomaterials 21, 2475 (2000).

20. M. Stevanovic, A. Radulovic, B. Jordovic, and D. Uskokovic, Poly(DL-lactide-co-glycolide) nanospheres for the sustained release of folic acid. J. Biomed. Nanotechnol. 4, 349 (2008).

21. Y. Y. Yang, T. S. Chung, and N. P. Ng, Morphology, drug distribution, and in vitro release profiles of biodegradable polymeric microspheres containing protein fabricated by double-emulsion solvent extraction/evaporation method. Biomaterials 22, 231 (2001).

22. Y. Y. Yang, T. S. Chung, X. L. Bai, and W. K. Chan, Effect of preparation conditions on morphology and release profiles of biodegradable polymeric microspheres containing protein fabricated by double-emulsion method. Chem. Eng. Sci. 55, 2223 (2000).

23. J. Panyam, M. M. Dali, S. K. Sahoo, W. Ma, S. S. Chakravarthi, G. L. Amidon, R. J. Levy, and V. Labhasetwar, Polymer degradation and in vitro release of a model protein from poly $(\mathrm{D}, \mathrm{L}$ lactideco-glycolide) nano- and microparticles. J. control Release 92, 173 (2003).

24. D. G. Serota, A. K. Thakur, B. M. Ulland, J. C. Kirschman, N. M. Brown, R. H. Coots, and K. Morgareidge, A two-year drinking-water study of dichloromethane in rodents. I: Rats. Food Chem. Toxicol. 24, 951 (1986).

25. J. Kanno, J. F. Foley, F. Kari, M. W. Anderson, and R. Maronpot, Effect of methylene chloride inhalation on replicative DNA synthesis in the lungs of female B6C3F mice. Environ. Health Persp. 101, 271 (1993).

26. C. C. DeMerlis and D. R. Schoneker, Review of the oral toxicity of polyvinyl alcohol (PVA). Food Chem. Toxicol. 41, 319 (2003).

27. T. Kimoto, R. Hosokawa, T. Kubo, M. Maeda, A. Sano, and Y. Akagawa, Continuous administration of basic fibroblast growth factor (FGF-2) accelerates bone induction on rat calvaria-An application of a new drug delivery system. J. Dent Res. 77, 1965 (1998).

28. S. J. Peter, L. Lu, D. J. Kim, G. N. Stamatas, M. J. Miller, M. J. Yaszemski, and A. G. Mikos, Marrow stromal osteoblast function on a poly(propylene fumarate) $/ \beta$-tricalcium phosphate biodegradable orthopaedic composite. Biomaterials 21, 1207 (2000).

29. A. Jaklenec, A. Hinckfuss, B. Bilgen, D. M. Ciombor, R. Aaron, and E. Mathiowitz, Sequential release of bioactive IGF-1 and TGF- $\beta 1$ from PLGA microsphere-based scaffolds. Biomaterials 29, 1518 (2008).

30. A. J. DeFail, C. R. Chu, N. Izzo, and K. G. Marra, Controlled release of bioactive TGF- $\beta 1$ from microspheres embedded within biodegradable hydrogels. Biomaterials 27, 1579 (2006).

31. N. Kikuchi, C. Kitamura, T. Morotomi, Y. Inuyama, H. Ishimatsu, Y. Tabata, T. Nishihara, and M. Terashita, Formation of dentin-like particles in dentin defects above exposed pulp by controlled release of fibroblast growth factor 2 from gelatin hydrogels. $\underline{J}$. Endodont 33, 1198 (2007).

32. J. Crank, The Mathematics of Diffusion, 2nd edn., Oxford Science Publications, Oxford University Press, Oxford (1975). 